\title{
To Report a Successful Birth Post Trans-Vaginal Reconstruction of a Uterine Scar
}

\author{
Graeme Wertheimer ${ }^{1 *}$, Sean Heinz-Partington ${ }^{2}$, John Pardey ${ }^{3}$ and George Hardas ${ }^{4}$ \\ ${ }^{1}$ University of Notre Dame, Australia \\ ${ }^{2}$ Laparoscopic Gynaecology Fellow, Nepean Hospital, NSW, Australia
}

${ }^{3}$ Adjunct Associate Professor, Sydney University, Australia

${ }^{4}$ Director, Sydney West Advanced Pelvic Surgery Unit (SWAPS), Sydney, NSW, Australia

Submission: October 03, 2018 ; Published: October 15, 2018

*Corresponding author: Graeme Wertheimer, University of Notre Dame, Australia, Tel: 0459 291 290; Email: Graeme.wertheimer1@my.nd.edu.au

\begin{abstract}
Endometrial and myometrial disruption or scar dehiscence may increase the risk of complications during and/or after pregnancy. Caesarean scar dehiscence (CSD) is life-threatening. It can lead to postpartum haemorrhage resulting in increased maternal morbidity or even death if not diagnosed and managed promptly [1]. Caesarean scar pregnancies are a form of rare ectopic pregnancy. They carry a high risk of uterine rupture with significant morbidity and potential loss of fertility [2].
\end{abstract}

Transvaginal ultrasonography with high resolution transducers and sonohysterography has been recommended as the first choice for screening caesarean scar defect, as it is simple, non-invasive, low cost and has the same results as hysteroscopy [1,3]. Once the diagnosis is confirmed, transvaginal repair may be performed with a good post-operative anatomical result as first described by Khoshnow and Pardey [4]. This is a case report of a successful transvaginal reconstruction of a uterine scar followed by an uncomplicated pregnancy and birth.

Keywords: Gynaecology; Obstetrics; Pregnancy; Reconstruction; Surgery

Abbreviations: CSD:Caesarean Scar Dehiscence; DC: Dilatation and Curettage

\section{Patient}

Patient $\mathrm{X}$ is a 36yo G8P4 with an unfortunate obstetric history. She had her first pregnancy in 2007 at the age of 25 which resulted in a missed miscarriage. A dilatation and curettage of the uterus (D\&C) was performed with no complications. In 2008, she underwent an elective caesarean section at 37 weeks due to severe intrauterine growth restriction. The child was born with an unbalanced chromosome translocation and subsequently died at 3 months of age. On follow up maternal testing, patient $\mathrm{X}$ was found to be a carrier for a balanced chromosomal translocation. All following pregnancies were achieved through IVF with preimplantation genetic diagnosis. In 2009, she presented at 19 weeks' gestation with PV spotting, vaginal discharge and pelvic pain. On ultrasound, her cervix was noted to be $3 \mathrm{~cm}$ dilated. She underwentan emergency cervical cerclage for cervical incompetence.

At 21 weeks, she had preterm premature rupture of membranes requiring removal of the cervical suture and subsequently lost the pregnancy. Delivery was complicated bya retained placenta that required manual removal and curettage. Histopathology of the placenta was within normal limits. Cervical cerclage was performed at 13 weeks for the next two pregnancies, both of which resulted in healthy children via planned caesarean sections at 38 weeks. Dense pelvic adhesions complicated the third caesarean section with an extremely deficient lower uterine segment. An inadvertent bladder perforation at the dome was sustained which was repaired in two layers. Cystogram post repair showed no bladder leakage. She was treated for wound infection and a urinary tract infection post procedure and was advised to wait more than 12 months before trying to conceive again due to a thin lower uterine segment.

Before her next pregnancy, she underwent a hysteroscopy that showed a clear defect along the left side of the caesarean scar requiring transvaginal reconstruction before future pregnancies. Thiswas successfully conducted in 2015. In 2016 she fell pregnant but had fetal demise at 14 weeks gestation despite viability confirmed 1 week prior when the cervical cerclage was performed. Later in 2016, she again had successful implantation, however, this was later discovered to be an anembryonic pregnacy. Definitive treatment was conducted by suction D\&C. In late 2017 she had her most recent pregnancy. In August 2018, she gave birth to a healthy baby via caesarean section at 38 weeks with nil complications. A well-formed uterine scar was noted. 


\section{Journal of Gynecology and Women's Health}

\section{Intervention}

In July 2015, patient X underwent lower uterine segment reconstructive surgery. The goal was to revise the uterine scar via the transvaginal approach, mobilising the bladder away and lifting it off the uterus to allow visualisation of the defect and debridement to both the superior and inferior surface. Examination and investigations revealed a deep scar defect in the cervical canal with what almost looked like a pin hole complete gap on the left anteriorly. There appeared to be a defect externally with the bladder folded down into a groove in the anterior wall of the uterus. The dissection was much more straightforward than anticipated. The bladder was lifted off the lower segment using an approach much as one would for a vaginal hysterectomy.

The bladder was mobilised without injury, and the defect was debrided with a combination of pituitary rongeurs for the lower edge and cervical biopsy forceps for the upper edge. Closure was performed with eight \#1 vicryl sutures which were all passed, clipped and tied in sequence when satisfactorily aligned. Once haemostasis was confirmed and the lower segment was intact, the vagina was closed with vicrylrapide. A cystoscopy was successfully performed, ensuring there was no injury to the bladder.

\section{Measurements and Main Result}

Patient X recovered very well. On day four post-surgery, an ultrasound showed a small pocket on the left side of the uterus, but the state of collagen was much improved compared to prereconstruction. The surgeon was confident that the lower uterine segment was much thicker than before despite the pocket to one side and the chance of a catastrophic uterine rupture in a subsequent pregnancy was remote in the extreme.

\section{Pre-surgical resconstruction of scar}

- Indication: 32yo, pre-op for LSCS scar defect, LSCS x 3

- Method:Transvaginal ultrasound

- The uterus was anteverted and of normal size: Long/ AP $/ \operatorname{Tr} 6.8 \mathrm{~cm}, 3.6 \mathrm{~cm}, 5.4 \mathrm{~cm}$. Vol $68.3 \mathrm{~cm} 3$. There was no obvious internal pocket seen at the LSCS scar site though there was a degree of wedging from the serosal surface inwards.

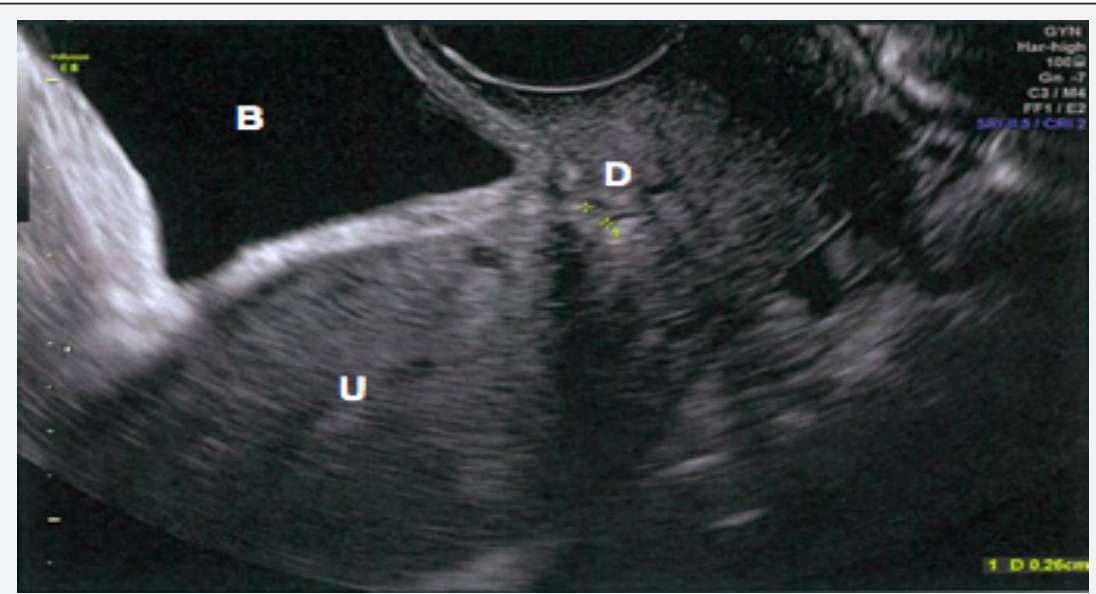

Figure 1: Ultrasound image showing uterine defect prior to surgery. Ultrasound was performed by the Ultrasound for Women, Penrith.(B = Bladder, $\mathrm{D}=$ Scar Defect, $\mathrm{U}=$ Uterus).

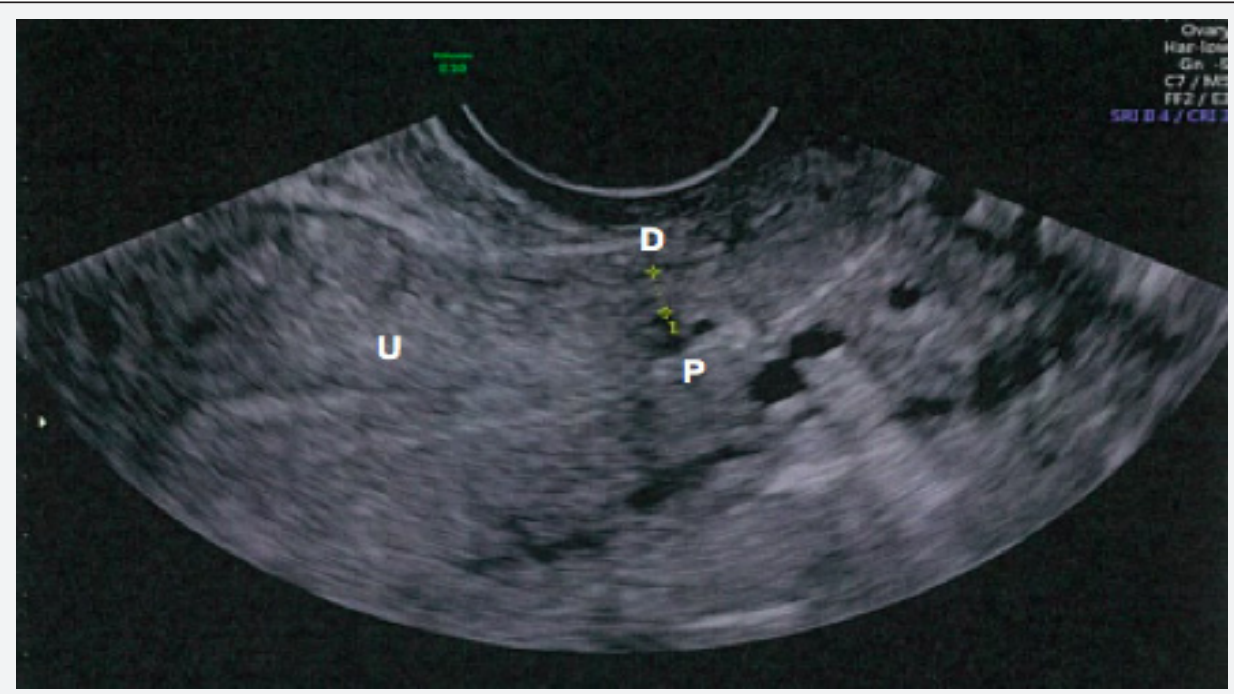

Figure 2: Ultrasound image showing pocket and $10 \mathrm{~mm}$ thick uterine scar post-surgical reconstruction. Ultrasound was performed by the Ultrasound for Women, Penrith. ( $D=$ Defect, $P=$ Pocket, $U$ = Uterus). 


\section{Journal of Gynecology and Women's Health}

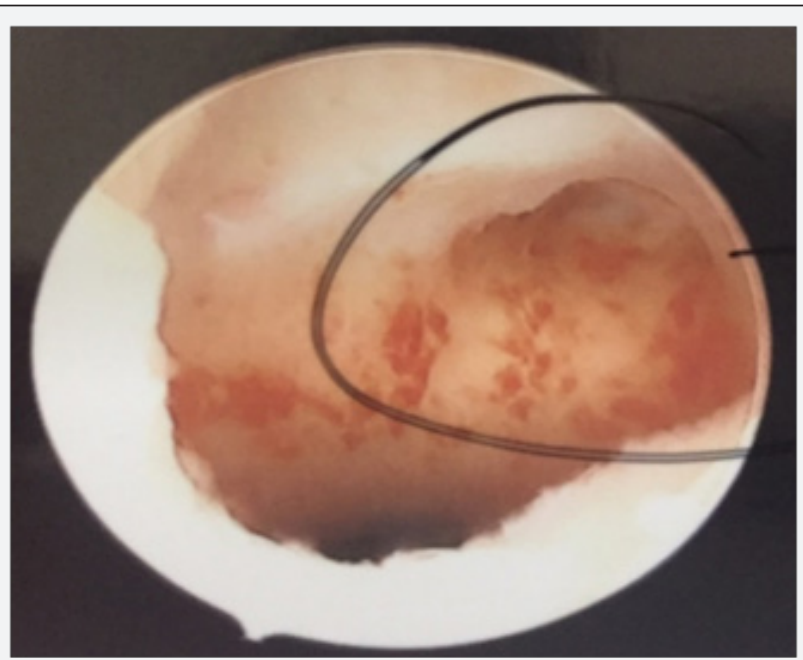

Figure 3: Left sided lower segment defect as seen on hysteroscopy prior to reconstruction.

(Arrow identifying defect).

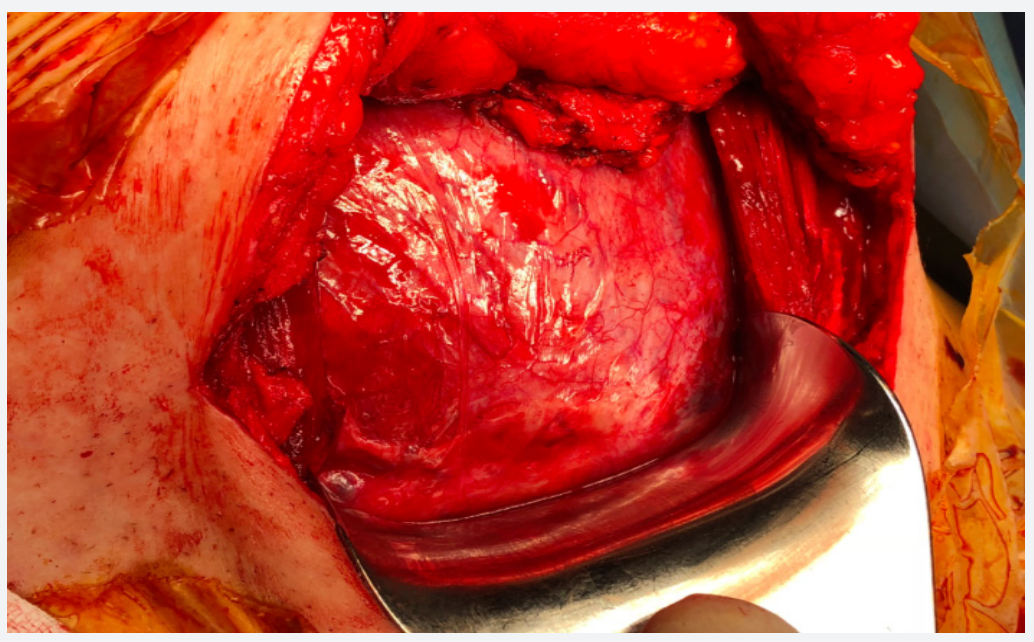

Figure 4: Well formed uterine scar as seen during caesarean section post reconstruction.

At its thinnest point $2.6 \mathrm{~mm}$ of myometrium was found. References

Endometrial thickness totals $3.4 \mathrm{~mm}$ (Figure 1-4).

\section{Conclusion}

Patient $\mathrm{X}$ had an unfortunate obstetric history leading to her requiring lower uterine reconstructive surgery. This surgery was successfully carried out, and patient x recovered well. Postsurgery, patient $\mathrm{x}$ had two unsuccessful pregnancies via IVF embryo transfer. In 2017 she had successful implantation, and the pregnancy continued without complication. She delivered a healthy baby on the $2^{\text {nd }}$ of August 2018. The scar from the reconstructive surgery was noted to be thick and very successfully reconstructed. This case report is an example of how reconstructive surgery can allow successful pregnancies for high riskwomen(Figures 1 and 2).

\section{Acknowledgement}

Ultrasound for Women, Penrith for supplying the ultrasound images.
1. Basic E, Basic-Cetkovic V, Kozaric H, Rama A (2012) Ultrasound evaluation of uterine scar after cesarean section. Acta Inform Med 20(3): 149-153.

2. Klemm P, Koehler C, Mangler M, Schneider U, Schneider A, et al. (2005) Laparoscopic and vaginal repair of uterine scar dehiscence following cesarean section as detected by ultrasound. J Perinat Med 33(4): 324331.

3. Fabres C, Aviles G, Jara DL, Escalona C, Munoz J, et al. (2003) The cesarean delivery scar pouch: clinical implications and diagnostic correlation between transvaginal sonography and hysteroscopy. J Ultrasound Med 22(7): 695-700.

4. Khoshnow Q Pardey J, Uppal T (2010) Transvaginal repair of caesarean scar dehiscence. Aust NZJ Obstet Gynaecol 50(1): 94-95. 
(C) (i) This work is licensed under Creative BY DOI: 10.19080/JGWH.2018.12.555836
Your next submission with Juniper Publishers will reach you the below assets

- Quality Editorial service

- Swift Peer Review

- Reprints availability

- E-prints Service

- Manuscript Podcast for convenient understanding

- Global attainment for your research

- Manuscript accessibility in different formats ( Pdf, E-pub, Full Text, Audio)

- Unceasing customer service

Track the below URL for one-step submission https://juniperpublishers.com/online-submission.php 